Agricultura urbana 


\title{
Agricultura urbana no município de São Paulo: considerações sobre produção e comercialização
}

\author{
ANDRÉ RUOPPOLO BIAZOTI, ${ }^{I}$ \\ VITÓRIA OLIVEIRA P. DE SOUZA LEÃO, ${ }^{I I}$ \\ RAFAEL JUNQUEIRA BURALLI III \\ ¿ THAIS MAUAD ${ }^{I V}$
}

\section{Introdução}

A

TUALMENTE, os sistemas alimentares enfrentam muitos desafios, como as ameaças de pragas agrícolas, as mudanças climáticas, a sustentabilidade dos processos produtivos, os custos financeiros e ambientais de transporte e o aumento do consumo de alimentos processados e ultraprocessados (Afshin et al., 2019; Willett et al., 2019). Principalmente nas zonas periféricas e menos abastadas das grandes cidades, nota-se destacada escassez de estabelecimentos alimentares, sobretudo que forneçam produtos in natura, sendo tais áreas caracterizadas como "desertos alimentares”. Nesses espaços, os desafios para a promoção de hábitos de vida mais saudáveis são maiores (Giatti et al., 2019; Borges et al., 2018).

Garantir a segurança alimentar e nutricional do Município de São Paulo (MSP), a maior cidade do Brasil, é um desafio imenso. Enquanto a falta de alimentos é um grave problema para as populações de menor renda, a falta de nutrientes essenciais, o sobrepeso, a obesidade e o sedentarismo podem afetar indivíduos de maior e menor renda, e resultar em um aumento de doenças crônicas e não-transmissíveis, como o diabetes, as doenças cardíacas, vasculares, entre outras (Swinburn et al., 2019; Willett et al., 2019).

Ainda que seja uma atividade reconhecidamente antiga (Nagib, 2016; Caldas; Jayo, 2019; Biazoti, 2020), a Agricultura Urbana (AU) tem sido apontada, mais recentemente, como elemento importante nos discursos e nas práticas que visam a soberania e a segurança alimentar e a proteção dos ecossistemas das cidades (Pessoa et al., 2006; Opitz el al., 2016). Diante da multiplicidade de formas que pode adquirir, o elemento central que define a AU é sua localização no interior e arredores das cidades e sua conexão íntima como o ecossistema 
urbano (Mougeot, 2000). Neste artigo, tratamos especificamente da agricultura circunscrita ao MSP, sem distinguir as zonas administrativas urbanas e rurais.

Reconhecer as diferentes formas da agricultura no MSP é importante para uma análise da produtividade agrícola e sua comercialização. Essa diversidade se relaciona com a multifuncionalidade da agricultura tanto no meio rural quanto no urbano, em que outros aspectos passam a ser relevantes para além da produtividade voltada ao mercado convencional (Carneiro; Maluf, 2005). Diversas hortas presentes no município são dedicadas ao autoconsumo, outras têm papel pedagógico e ativista na promoção da segurança alimentar e nutricional, onde a produtividade é um aspecto secundário (Biazoti, 2020; Nagib, 2016). Ao mesmo tempo, estão presentes, no município, agricultores familiares, empreendimentos agrícolas e fazendas produtivas com foco na comercialização de alimentos, plantas ornamentais e produção de animais de médio e pequeno portes (Valdiones, 2013).

Diante disso, o artigo buscou analisar a agricultura existente no MSP a partir da produção agropecuária e sua comercialização, evidenciando sua contribuição para o abastecimento alimentar da metrópole.

\section{Metodologia}

A metodologia deste artigo compreende a análise de dados secundários de pesquisas censitárias sobre a produção agrícola do MSP e de dados primários coletados em entrevistas semiestruturadas pelos autores com agricultores das diversas cadeias produtivas do município.

Realizou-se uma comparação da produção agrícola do MSP em bases de dados oficiais. Foram analisadas, principalmente, as informações contidas nos Censos Agropecuários de 2006 e 2017 do Instituto Brasileiro de Geografia e Estatística (IBGE) e do Levantamento Censitário das Unidades de Produção Agropecuário do Estado de São Paulo (Lupa), desenvolvido pela Coordenadoria de Desenvolvimento Rural Sustentável, da Secretaria de Agricultura e Abastecimento (CDR/SAA). Outros levantamentos, como o Cadastro do Produtor Rural (CPR) e o Cadastramento do Projeto Ligue os Pontos, também foram pesquisados, buscando apresentar a diversidade de informações existentes e sugerir a amplitude da agricultura no município.

Há diferenças conceituais importantes entre esses levantamentos. A unidade de análise utilizada pelo Censo é o "estabelecimento agrícola" e corresponde a "toda unidade de produção dedicada, total ou parcialmente, à exploração agropecuária, florestal ou aquícola, independente do seu tamanho, de sua forma jurídica [...], de sua localização [...], tendo como objetivo a produção...” (IBGE, 2019 , p.14). No Lupa, a Unidade de Produção Agropecuária (UPA) é definida como "conjunto de propriedades agrícolas contíguas e pertencentes ao mesmo proprietário; localizada dentro de um mesmo município; com área igual ou superior a 0,1 ha; e não destinada exclusivamente para lazer" (São Paulo, 2009, p.2). Dessa forma, para o Lupa, uma área de produção de um mesmo proprie- 
tário desmembrada em diferentes lotes para mais de um agricultor é considerada como uma unidade de produção agropecuária.

A Prefeitura Municipal de São Paulo, por meio da sua Supervisão de Abastecimento (Abast), realizou um levantamento de produtores denominado Cadastro de Produtor Rural (CPR), por meio dos técnicos agrícolas da Supervisão e da Secretaria do Verde e Meio Ambiente (SVMA). Apesar de ser o primeiro levantamento mais estruturado realizado em âmbito municipal sobre os agricultores existentes em São Paulo, ele é considerado um cadastramento informal e interno à prefeitura, pouco utilizado para a definição de políticas públicas.

O MSP ainda conta com o recente censo de agricultores da região sul, realizado em 2019 pelo projeto Ligue os Pontos, financiado pela Bloomberg Philantropies. O projeto surgiu com a vitória do MSP no Prêmio Mayor's Challenge Latin America 2016 e desenvolveu uma plataforma digital que pretende potencializar as políticas públicas relacionadas à cadeia de valor da agricultura local. Esse cadastro é considerado, hoje, o mais completo no que se refere ao perfil da agricultura realizada na região sul do MSP, evidenciando, principalmente, a agricultura realizada na zona rural.

A segunda frente metodológica do artigo concerne às informações acerca da comercialização. Parte dos dados apresentados neste artigo foi coletada ao longo da pesquisa de mestrado de Leão (2019) e corresponde a quatro entrevistas semiestruturadas realizadas com agricultores da zona leste do MSP durante os anos de 2018 e 2019. Além disso, em março de 2020 foram realizadas outras três entrevistas com enfoque na comercialização. Essas últimas escutas implicaram dois agricultores da zona norte, sendo um participante do Conselho de Desenvolvimento Rural Solidário e Sustentável de São Paulo e uma agricultora da zona sul, ativamente engajada com a agricultura da região.

É importante assinalar que as informações recolhidas junto aos agricultores não abarcam todos os canais de comercialização acessados pelas associações ou cooperativas em questão. $\mathrm{O}$ escoamento da produção familiar tende a ser dinâmico e diverso, adaptando-se às necessidades e às possibilidades dos agricultores, ante os entraves existentes no acesso aos mercados industrializados (Leão, 2019). Trata-se, portanto, de um recorte circunscrito a seu respectivo período de coleta e não pretende representar dados censitários. Essas informações são valiosas pois explicitam não só a falta de dados oficiais publicados sobre o tema, mas também as características dos canais de comercialização vinculados à $\mathrm{AU}$ e os papéis que desempenham para os produtores e consumidores das cidades.

Por fim, cabe ressaltar os apontamentos de Minayo (2017) acerca do estabelecimento de amostragem em pesquisas qualitativas. Segundo a autora, a sua construção deve levar em conta os objetivos da análise, tendo em vista o papel que os atores entrevistados desempenham em determinado grupo e a abrangência das informações que poderá passar. O presente artigo procurou tratar das ca- 
racterísticas dos canais de comercialização acessados pelos agricultores em questão e não tem como objetivo retratar a totalidade de tais experiências no MSP.

\section{Levantamento da produção agrícola}

No MSP, a agricultura pode ser caracterizada de várias formas e tipos. Essa diversidade representa as múltiplas formas de relação com natureza, bem como de apropriação do território urbano pelos cidadãos. O Quadro 1 sistematiza algumas tipologias de AU que podem ser descritas no MSP e que orientarão o levantamento e a análise de dados subsequente.

Quadro 1 - Tipos de agricultura urbana identificados do município de São Paulo

\begin{tabular}{l|l|c}
\hline Tipo de agricultura urbana & \multicolumn{1}{|c}{ Função primária ou orientação } & Comercialização \\
\hline Quintal produtivo (residencial) & Autoconsumo, recreação, paisagem, doação & Mínima \\
\hline Loteamento & $\begin{array}{l}\text { Autoconsumo, doação, venda de excedente, } \\
\text { segurança alimentar e nutricional }\end{array}$ & Ocasional \\
\hline Guerrilha & $\begin{array}{l}\text { Ativismo, ocupação de espaços públicos, } \\
\text { criação de paisagens comestíveis }\end{array}$ & Inexistente \\
\hline Horta comunitária & $\begin{array}{l}\text { Autoconsumo, ativismo, ocupação de espaços } \\
\text { públicos, segurança alimentar e nutricional, } \\
\text { comunidade. }\end{array}$ & Ocasional \\
\hline Horta institucional & $\begin{array}{l}\text { Autoconsumo, doação, educação, } \\
\text { reabilitação, capacitação e treino, venda } \\
\text { ocasional }\end{array}$ & Rara \\
\hline Horta urbana & $\begin{array}{l}\text { Autoconsumo, venda, segurança alimentar } \\
\text { e nutricional, abastecimento }\end{array}$ & Frequente \\
\hline Agricultura familiar & Autoconsumo,venda, abastecimento & Frequente \\
\hline Empreendimento agrícola & Venda, abastecimento & Sempre \\
\hline
\end{tabular}

Fonte: Adaptado de Biazoti e Sorrentino (2018).

Conhecer os tipos de agricultura urbana presentes em São Paulo é importante para perceber padrões, desafios e potencialidades inerentes às diversas formas em que se estruturam essas iniciativas. Assim, ao analisar a agricultura paulistana sob o enfoque da produtividade e da comercialização, é preciso observar, principalmente, as práticas cujo enfoque se dá na produção para a comercialização e no abastecimento de alimentos, como "horta urbana”, "agricultura familiar" e "empreendimento agrícola".

É importante destacar a ausência de dados acerca das outras tipologias de agricultura, relacionadas a práticas educativas, ativistas e de autoconsumo. Por sua baixa produtividade agrícola, pelo dinamismo das experiências e pela própria dificuldade na obtenção de dados, tais experiências são negligenciadas e invisibilizadas no território urbano. O reconhecimento público de todas as formas de agricultura realizadas, com suas nuances e peculiaridades ainda é um desafio encontrado por agricultores para se estabelecerem no território.

Por ser uma atividade de ainda pouca importância econômica quando comparado aos setores industrial e de serviços, pouca pesquisa foi destinada a 
entender e analisar o setor agrícola paulistano. No entanto, existem diferentes levantamentos censitários ao longo das duas últimas décadas que nos fornecem um panorama histórico mais recente da agricultura em São Paulo (Tabela 1).

Tabela 1 - Número de estabelecimentos agropecuários por estudo ou cadastro e ano

\begin{tabular}{l|l|l|l}
\hline Base de dado & $\begin{array}{l}\text { Número } \\
\text { de estabelecimentos }\end{array}$ & $\begin{array}{l}\text { Função primária } \\
\text { ou orientação }\end{array}$ & Comercialização \\
\hline $\begin{array}{l}\text { Cadastro do Produtor Rural } \\
(2012)\end{array}$ & 446 unidades de produção & & 5.000 ha \\
\hline $\begin{array}{l}\text { Levantamento Unidades } \\
\text { de Produção Agropecuária } \\
\text { (Lupa - 2007/2008) }\end{array}$ & 253 unidades de produção & 3.000 ha \\
\hline $\begin{array}{l}\text { Levantamento Unidades } \\
\text { de Produção Agropecuária } \\
\text { (Lupa - 2016/2017) }\end{array}$ & 323 unidades de produção & $\begin{array}{l}\text { (p02 pessoas } \\
\text { e mensalistas })\end{array}$ & $4.388,40$ ha \\
\hline $\begin{array}{l}\text { Censo Agropecuário - IBGE } \\
\text { (2006) }\end{array}$ & $\begin{array}{l}193 \text { estabelecimentos } \\
\text { agropecuários }\end{array}$ & 767 pessoas ocupantes & 8.000 ha \\
\hline $\begin{array}{l}\text { Censo Agropecuário - IBGE } \\
\text { (2017) }\end{array}$ & $\begin{array}{l}550 \text { estabelecimentos } \\
\text { agropecuários }\end{array}$ & $\begin{array}{l}1.945 \text { pessoas } \\
\text { ocupantes }\end{array}$ & 10.954 ha \\
\hline $\begin{array}{l}\text { Cadastramento Projeto Ligue } \\
\text { os Pontos - 2019 }\end{array}$ & $\begin{array}{l}\text { (apenas da Zona Sul } \\
\text { e que comercializam) }\end{array}$ & & \\
\hline
\end{tabular}

Fonte: Elaboração própria, adaptada de Biazoti (2020).

De acordo com o Lupa, em 2008, foram identificadas 253 UPA no MSP, atingindo uma área de cerca de 3.000 ha de produção agrícola. No Lupa realizado em 2016/2017, com dados preliminares divulgados apenas no final de 2019, foram identificadas $323 \mathrm{UPA}$, em sua maior parte com propriedades menores que 10 ha e com culturas temporárias, totalizando uma área de cerca de 4.388 ha no município e 802 pessoas envolvidas diretamente na produção, entre proprietários, familiares e mensalistas, conforme Tabela 2 (São Paulo, 2009; São Paulo, 2019).

A produção agrícola municipal, conforme o Lupa em comparativo entre os levantamentos de 2007/08 e 2016/2017, é apresentada na Tabela 3.

O Censo Agropecuário também traz dados interessantes. O Censo de 2006 indicava a presença de 193 estabelecimentos agropecuários no município, com 767 pessoas ocupantes e cerca de 193 produtores rurais, sendo 130 de agricultores familiares e 63 não familiares, com predominância de cultivo temporário (861 ha) e grande presença de áreas naturais (3.111 ha) e espaços construídos (1.836 ha).

Por sua vez, o Censo de 2017 indicou 550 estabelecimentos agropecuários com 1.945 pessoas ocupantes, com predominância de cultivo temporário (689 ha), áreas naturais destinadas à preservação (7.832 ha) e produção de flores (432 ha). Há um incremento de $65 \%$ do número de estabelecimentos em cerca de dez anos, além de um aumento de pouco mais que o dobro do número de ocupantes e de áreas naturais protegidas, conforme Tabela 4. 
Tabela 2 - Estatísticas Agrícolas, Município de São Paulo, Estado de São Paulo, Lupa 2007/2008 e 2016/2017

\begin{tabular}{l|l|l|l|c}
\hline \multicolumn{1}{c|}{ Item } & \multicolumn{2}{l|}{$\begin{array}{l}\text { Número de Unidade de Produção } \\
\text { Agropecuária (UPA) }\end{array}$} & \multicolumn{2}{l}{ Total de área (hectare) } \\
\hline & $2007 / 2008$ & $2016 / 2017$ & $2007 / 2008$ & $2016 / 2017$ \\
\hline Número UPA/Área total & 253 & 323 & $2.936,0$ & $4.388,4$ \\
\hline Cultura perene & 71 & 95 & 91,2 & 126,8 \\
\hline Cultura temporária & 205 & 265 & 968,0 & $1.019,6$ \\
\hline Pastagem & 19 & 49 & 250,4 & 415,9 \\
\hline Reflorestamento & 47 & 56 & 141,4 & 185,4 \\
\hline Vegetação natural & 154 & 230 & 964,8 & $1.815,7$ \\
\hline Descanso & 156 & 177 & 342,4 & 588,2 \\
\hline UPA com $(0,1)$ ha & 29 & 46 & 19,4 & 26,4 \\
\hline UPA com (1, 2) ha & 36 & 41 & 58,9 & 66,6 \\
\hline UPA com $(2,5)$ ha & 77 & 82 & 266,9 & 294,3 \\
\hline UPA com (5, 10) ha & 35 & 42 & 267,6 & 324,6 \\
\hline UPA com $(10,20)$ ha & 35 & 54 & 489,0 & 764,7 \\
\hline UPA com (20,50) ha & 30 & 41 & 928,7 & $1.259,5$ \\
\hline UPA com (50, 500) ha & 11 & 17 & 905,5 & $1.652,3$ \\
\hline
\end{tabular}

Fonte: Elaboração própria, a partir das tabelas em São Paulo (2009); São Paulo (2019).

Os dados apresentados, no que se refere às séries históricas do Censo Agropecuário e do Lupa, possibilitam observar que há um aumento na produção e no número de agricultores existentes no MSP nos últimos 15 anos. A agricultura tem se desenvolvido e sido ampliada, apresentando um crescimento de cerca de 22\% no número de UPA e 33\% em área de produção entre 2007/2008 e 2016/2017, segundo o Lupa. No que se refere às culturas temporárias, o Lupa apresenta um aumento no número de UPA (22\% entre 2007 e 2016) e na área cultivada (apenas 5\% entre 2007 e 2016), enquanto o Censo Agropecuário do IBGE apresenta um incremento de 58\% no número de estabelecimento, porém uma redução de $25 \%$ da área destinada a esse tipo de lavoura. Em relação à lavouras permanentes, o Lupa indica crescimento de $25 \%$ no número de UPA e $28 \%$ na área produtiva, enquanto o Censo Agropecuário do IBGE indica aumento de $75 \%$ no número de estabelecimentos e $82 \%$ de crescimento em área. 
Tabela 3 - Área Cultivada das principais culturas (ha), Município de São Paulo, Estado de São Paulo, 2007/2008 e 2016/2017, segundo dados do Lupa

\begin{tabular}{|c|c|c|c|c|}
\hline \multirow[t]{2}{*}{ Item } & \multicolumn{2}{|c|}{$\begin{array}{l}\text { Número de Unidade de Produção } \\
\text { Agropecuária (UPA) }\end{array}$} & \multicolumn{2}{|c|}{ Total de área (hectare) } \\
\hline & 2007/2008 & $2016 / 2017$ & 2007/2008 & $2016 / 2017$ \\
\hline Floricultura para corte & 50 & 44 & 260,7 & 231,1 \\
\hline Alface & 80 & 102 & 170,0 & 222,3 \\
\hline Braquiária & 16 & 35 & 155,4 & 247,2 \\
\hline Chuchu & 36 & 36 & 141,2 & 97,5 \\
\hline Eucalipto & 40 & 48 & 134,3 & 170,2 \\
\hline Couve & 84 & 93 & 110,0 & 94,5 \\
\hline Brócolis & 58 & 65 & 89,1 & 77,3 \\
\hline Couve-flor & 57 & 56 & 82,8 & 61,2 \\
\hline Repolho & 35 & 56 & 67,6 & 76,2 \\
\hline Beterraba & 52 & 55 & 60,8 & 46,5 \\
\hline Milho & 12 & 28 & 50,3 & 78,1 \\
\hline $\begin{array}{l}\text { Viveiro de flores } \\
\text { e ornamentais } \\
\end{array}$ & 20 & 24 & 49,0 & 71,2 \\
\hline Mandioca & 4 & 26 & 1,4 & 13,2 \\
\hline Horta doméstica & 8 & 23 & 2,9 & 9,3 \\
\hline Banana & 7 & 25 & 2,7 & 31,1 \\
\hline Pomar doméstico & 28 & 51 & 18,5 & 20,9 \\
\hline Cenoura & 19 & 28 & 17,9 & 19,2 \\
\hline Acelga & 15 & 16 & 16,5 & 15,4 \\
\hline Cebolinha & 35 & 43 & 14,7 & 16,6 \\
\hline $\begin{array}{l}\text { Ervas medicinais } \\
\text { e aromáticas }\end{array}$ & 7 & 24 & 2,2 & 17,5 \\
\hline Abóbora & 2 & 16 & 10,0 & 17,4 \\
\hline
\end{tabular}

Fonte: Elaboração própria, a partir das tabelas em São Paulo (2009); São Paulo (2019). 
Tabela 4 - Dados de produção de lavouras permanentes, temporárias e pastagens no município de São Paulo, segundo dados do Censo Agropecuário 2006 e 2017

\begin{tabular}{|c|c|c|c|c|c|c|}
\hline \multirow[t]{2}{*}{ Tipo de lavoura } & \multicolumn{2}{|c|}{$\begin{array}{l}\text { Número de } \\
\text { estabelecimentos }\end{array}$} & \multicolumn{2}{|c|}{ Área destinada (ha) } & \multicolumn{2}{|c|}{ Valor estimado da produção $(\mathrm{R} \$)$} \\
\hline & 2006 & 2017 & 2006 & 2017 & 2006 & 2017 \\
\hline Lavoura permanente & 46 & 184 & 60 & 343 & $\begin{array}{l}438.000 \\
\text { (apenas banana) }\end{array}$ & $1.520 .000,00$ \\
\hline Lavoura temporária & 139 & 335 & 861 & 689 & $\begin{array}{l}67.000 \\
\text { (mandioca, cana, } \\
\text { feijão e milho) }\end{array}$ & $371.000,00$ \\
\hline Cultivo de flores & 21 & 98 & 77 & 432 & & \\
\hline Pastagens naturais & 46 & 72 & 542 & 317 & & \\
\hline Pastagens plantadas & 15 & 24 & 110 & 143 & & \\
\hline
\end{tabular}

Fonte: Elaboração própria, com base nas tabelas em IBGE $(2006 ; 2018)$.

Tabela 5 - Dados de produção mais relevantes no município de São Paul - Censo Agropecuário 2006 e 2017

\begin{tabular}{|c|c|c|c|c|}
\hline \multirow[t]{2}{*}{ Cultura } & \multicolumn{2}{|c|}{ Número de estabelecimentos } & \multicolumn{2}{|c|}{ Produção } \\
\hline & 2006 & 2017 & 2006 & 2017 \\
\hline Banana (ton) & 17 & 41 & 371 & 293 \\
\hline Cana de açúcar (ton) & 14 & 14 & 8 & 17 \\
\hline Feijão (ton) & 28 & 32 (aprox.) & 3 & 8 \\
\hline Mandioca (ton) & 43 & 96 & 55 & 110 \\
\hline Milho (ton) & 15 & 30 & 8 & 71 \\
\hline Abóbora (ton) & & 28 & & 35 \\
\hline Galinhas (un) & 43 & 168 & 3.000 & 7.000 \\
\hline Gado (un) & 19 & 59 & 507 & 859 \\
\hline Gado (leite - litros) & 19 & 39 & 69.000 & 202.000 \\
\hline Cabras (un) & 4 & 20 & 60 & 322 \\
\hline Codornas (un) & & 6 & & 120.031 \\
\hline Patos e Gansos (un) & & 40 & & 919 \\
\hline Suínos (un) & 39 & 51 & 4.000 & 1.500 \\
\hline
\end{tabular}

Fonte: Elaboração própria, com base nas tabelas em IBGE $(2006 ; 2018)$. 


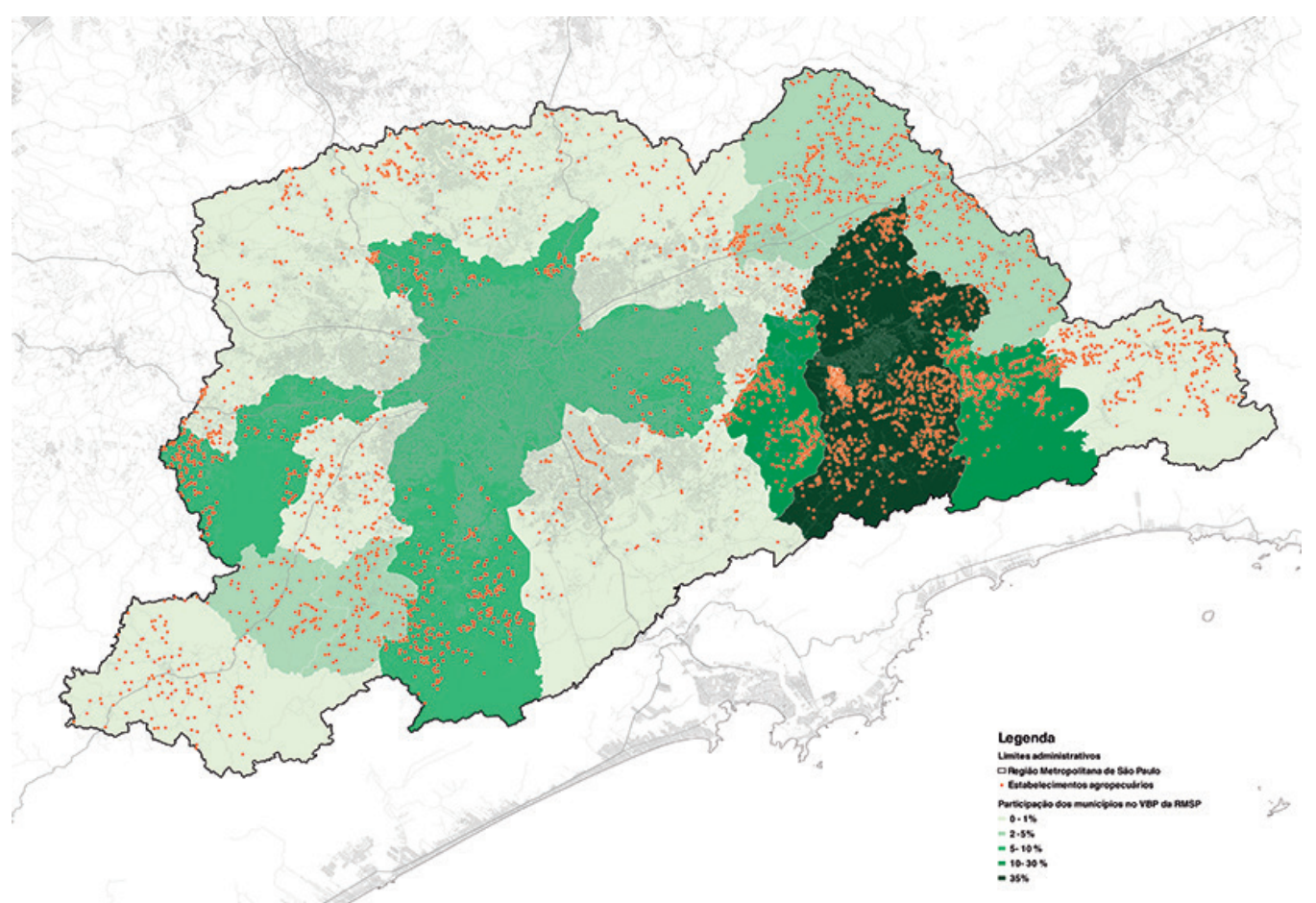

Fonte: Instituto Escolhas e Urbem (2020).

Figura 1 - Estabelecimentos agropecuários e participação dos municípios no Valor Bruto da Produção (VBP) da Região Metropolitana de São Paulo - Censo Agropecuário IBGE 2017.

Tabela 6 - Distribuição e área das Unidade de Produção Agrícola contidas no Cadastro do Produtor Rural (CPR) - 2012

\begin{tabular}{l|l|l}
\hline Região & $\begin{array}{l}\text { Número de Unidade de } \\
\text { Produção Agropecuária } \\
\text { (UPA) }\end{array}$ & Área total (ha) \\
\hline Sul & 312 & $4.642,20$ \\
\hline Norte & 42 & 184,15 \\
\hline Leste & 48 & 134,71 \\
\hline Total & 402 & $4.961,06$ \\
\hline
\end{tabular}

Fonte: Valdiones (2013). 
Outro levantamento, o Cadastro do Produtor Rural, analisado por Valdiones (2013), identificou que, no município, existem aproximadamente 446 Unidades de Produção Agropecuária (UPA), ocupando uma área total de 5.000 ha e distribuídas principalmente nas periferias das regiões norte, sul e leste (Valdiones, 2013, p.87-90).

Conforme cadastramento realizado no âmbito do projeto Ligue os Pontos, o município de São Paulo possui cerca de 646 unidades de produção agropecuária, sendo 524 na zona sul, 61 na zona leste e 61 na zona norte. Em relação à zona sul, foram identificadas 1.469 pessoas envolvidas, segundo a base consolidada do projeto, com área total aproximada de 2.313,38 hectares.

A agricultura na região sul do MSP, onde a produção é mais expressiva, é tipicamente familiar, sendo $64 \%$ proprietários, $78 \%$ que moram nas propriedades e 65\% com mão de obra exclusivamente familiar (São Paulo, 2020). Além disso, $79 \%$ das UPA cultivam frutíferas, apesar de apenas $16 \%$ de fato comercializarem essas frutas, e grande parte produz e comercializa folhosas, legumes, raízes e ervas aromáticas $(65 \%)$. Também há uma vasta produção de plantas ornamentais (em $45 \%$ das UPA), mas apenas $19 \%$ de fato comercializa e acessa os mercados dessa cadeia produtiva. A produção animal também foi evidenciada em 218 UPA, com a produção para comercialização de galinhas e frangos (89\%), de ovos $(83 \%)$, de porcos $(21 \%)$ e de mel $(6 \%)$. No total, $54 \%$ das UPA têm renda bruta agrícola inferior a $\mathrm{R} \$ 1.000,00 / \mathrm{mês}$ e $4 \%$ possuem renda agrícola superior a R\$20.000,00/mês (São Paulo, 2020).

De acordo com o CPR e com o Lupa, a maioria das propriedades tem cerca de 0,1 a 5 ha, exceto na região sul, onde há fazendas que chegam a ser maiores que 50 ha. Valdiones (2013) demonstra que boa parte dos agricultores urbanos do município possui a propriedade da terra, muitos deles adquiridos por herança. Apenas na região norte e em São Mateus, na região leste, é que há outras formas de posse da terra, como o arrendamento e a contratação por comodato. Nos dados do Censo Agropecuário 2017, assim como no cadastramento do Ligue os Pontos, também há indicação de uma maioria proprietária nos estabelecimentos agropecuários (426 unidades).

$\mathrm{Na}$ zona norte $(\mathrm{ZN})$, foram identificados 140 estabelecimentos no Censo Agropecuário 2017. Há predominância de produção de culturas temporárias que são comercializadas principalmente para atacadistas, feiras e diretamente para o consumidor final. Destaca-se na região a produção de animais realizada por mais da metade dos agricultores, onde a suinocultura e avicultura se destacam, apesar de enfrentarem problemas ambientais.

$\mathrm{Na}$ zona leste (ZL), foram identificados 99 estabelecimentos agropecuários no Censo Agropecuário 2017. Nessa região, é possível distinguir agricultores que cultivam em terrenos ociosos, em terrenos com linhas de transmissão de energia ou terrenos sobre adutoras de água e esgoto. A área produtiva total desse grupo tem destaque para a fruticultura (perene) e a produção de hortaliças (temporária) com comercialização direta ao consumidor final. 
Na zona sul (ZS) se encontra a maior parte de unidades de produção agropecuária no município, chegando a 309 estabelecimentos conforme o Censo Agropecuário 2017 e 428 UPA conforme o credenciamento do Ligue os Pontos. As áreas de produção são mais extensas nessa região, apesar da maior parte ter tamanho de até 5 ha. Culturas temporárias, como a olericultura, são as mais presentes, com sistemas preponderantemente convencionais de produção. Também se destaca a produção de plantas ornamentais e a silvicultura, assim como a produção animal de frangos, galinhas, ovos e suínos.

Os dados existentes no CPR, no Censo Agropecuário, no Lupa e no cadastramento do Ligue os Pontos não são suficientes para possibilitar uma análise completa de todos os tipos de agricultura urbana do município. Hortas institucionais, comunitárias, quintais produtivos e outras práticas de menor escala permanecem invisibilizadas no retrato geral da agricultura da cidade, apesar de sua importância em diversas esferas da vida urbana. Na realidade, não há estudos que consigam apreender em sua totalidade as práticas de agricultura urbana, tendo em vista sua dinâmica e a flexibilidade de formas que pode assumir.

Para além dos levantamentos governamentais, também é digno de nota o mapeamento realizado por Baron (2017), consolidando diversas fontes de dados, governamentais ou não, e pesquisas acadêmicas, de forma a identificar hortas urbanas na Região Metropolitana de São Paulo (RMSP). O autor identificou 412 hortas em onze municípios da RMSP, com destaque para os municípios de São Paulo, Diadema, Santo André e Embu. Assim, pode-se considerar um avanço no que diz respeito a identificar iniciativas que transcendem um olhar para agricultura urbana pautado apenas no que diz respeito ao abastecimento alimentar da metrópole (Baron, 2017).

\section{Considerações acerca da comercialização}

O município de São Paulo é conhecido por acolher a maior central de abastecimento de frutas, legumes, verduras, flores, ovos, pescados e outros itens hortícolas da América Latina. Trata-se do Entreposto Terminal de São Paulo (ETSP), da Companhia de Entrepostos e Armazéns Gerais de São Paulo (Ceagesp), onde chegam produtos variados de mais de 1.500 municípios do Brasil e de 18 países (Ceagesp, 2020). As mais de 3,4 milhões de toneladas de alimentos frescos que passam anualmente pela Ceagesp (2020) são distribuídas nas 871 feiras livres cadastradas no município (São Paulo, 2020), direcionadas para os diversos estabelecimentos comerciais e de processamento de alimentos, além das casas dos consumidores que frequentam o mercado de varejo da Companhia.

A capital paulista ainda conta com 14 mercados municipais, 17 sacolões municipais (São Paulo, 2020) e outras centrais de distribuição de alimentos privadas, tais quais a do GPA e Grupo Carrefour, ambas localizadas na Região Metropolitana de São Paulo e vinculadas a 483 lojas na cidade (GPA, 2020; Carrefour, 2020). Além desses canais de distribuição e comercialização, a cidade também é abastecida por programas públicos, como o Programa Nacional 
de Alimentação Escolar (PNAE), que forneceu 464,4 milhões de refeições em 2018 (São Paulo, 2018) para instituições municipais de ensino básico.

O MSP soma, portanto, números expressivos relacionados aos canais de distribuição e comercialização e é intensamente abastecida, ainda que de forma desigual tendo em vista as características e a qualidade dos alimentos. Por detrás de tantos números surpreendentes, encontram-se as diversas regiões do Brasil e afora, umas mais distantes, outras mais próximas, engajadas com a agricultura e a produção de alimentos que sustentam a metrópole paulista. A Região Metropolitana de São Paulo é uma delas e se destaca historicamente, pela produção de horticultura no chamado Cinturão Verde.

O acesso aos canais de comercialização desempenha um papel importante para a manutenção da agricultura no município, visto que garante parte da renda para os produtores, favorecendo a sua permanência na terra e a reprodução social da atividade agrícola como alternativa viável. Além disso, muitas vezes, esses canais suprem a demanda por alimentos frescos em áreas onde o seu acesso é mais escasso ou de menor qualidade ou ainda onde são vendidos a preços elevados, como é o caso dos produtos orgânicos (Leão, 2019). No entanto, não são poucos os desafios encontrados pelos agricultores em acessar o sistema de distribuição e comercialização do MSP, sobretudo para aqueles produtores familiares em menor escala. Seja pela escala da produção, pelo volume produzido, pelo preço vendido a agentes intermediários ou por questões logísticas, a entrada nos grandes canais de comercialização nem sempre é uma realidade para os agricultores.

Além de atividades sociais, educativas, esportivas, religiosas e aquelas voltadas ao turismo rural e à conservação ambiental, a produção agropecuária paulistana desenvolve inúmeras cadeias de produção e consumo. Dentre tais cadeias, é possível destacar a Cadeia de Horticultura e de Culturas Temporárias, a Cadeia de Flores e Plantas Ornamentais, a Cadeia da Suinocultura e a Cadeia de Avicultura. Há outras cadeias produtivas no município, associadas à produção de frutas e culturas perenes, à produção florestal e à piscicultura, que são de menor expressão.

A cadeia de Horticultura e Culturas Temporárias é a maior em termos de abrangência de mercados. Ela é caracterizada, principalmente, pela produção de banana, diversas culturas folhosas, tubérculos, Plantas Alimentícias Não Convencionais (Panc) entre outros produtos. O quadro a seguir sintetiza os canais de comercialização acessados pelos nossos interlocutores. 
Tabela 7 - Relação de canais de comercialização: horticultura e culturas temporárias

\begin{tabular}{l|l}
\hline $\begin{array}{l}\text { AAZL - Zona Leste } \\
(2019)\end{array}$ & $\begin{array}{l}\text { Feira do Shopping Anália Franco, Feira Orgânica do Parque do Carmo, } \\
\text { Feira Orgânica do Ceret (Tatuapé), Feira Orgânica de São Miguel, Instituto } \\
\text { Feira Livre (Centro), Cestas do Sesc Itaquera, venda direta nas áreas } \\
\text { de produção, venda em uma loja especializada em produtos orgânicos } \\
\text { de uma das agricultoras na região. }\end{array}$ \\
\hline $\begin{array}{l}\text { Agroverde - Zona Norte } \\
(2020) \\
(2019)\end{array}$ & $\begin{array}{l}\text { Ponto de venda no Jardim Damasceno, Jardim Paulistano e Jardim } \\
\text { Antártica. } \\
\text { Entrega de cestas com produtos selecionados para condomínios próximos, } \\
\text { para mercados de bairro e venda de porta em porta nas ruas residenciais. }\end{array}$ \\
\hline $\begin{array}{l}\text { Cooperapas - Zona Sul } \\
\text { (2020) }\end{array}$ & $\begin{array}{l}\text { Pela Cooperativa: Feira do Parque Ibirapuera, Feira do Parque da Água } \\
\text { Branca, Rede Sesc (diversas unidades), Restaurantes particulares } \\
\text { (Itaim Bibi), Instituto Feira Livre (Centro), Instituto Chão (Pinheiros) } \\
\text { e Instituto Baru (Butantã) e Subprefeitura de Parelheiros. } \\
\text { Vendas particulares: feiras livres, venda direta na área de produção } \\
\text { e revenda para sistemas de cestas. }\end{array}$ \\
\hline Outros produtores da & Ceagesp, feiras livres e feirantes, mercados de bairro e Sacolões. \\
\hline
\end{tabular}

Fonte: Elaboração própria.

A Associação dos Agricultores da Zona Leste (AAZL) escoa sua produção majoritariamente para a ZL de São Paulo, isto é, mantém o alimento no território em que foi produzido. Isso se dá, também, em razão do custo de transporte constituir um fator limitante para esses agricultores, bem como as pequenas áreas que possuem para produzir, não permitindo a venda em escala maior para os programas de abastecimento, por exemplo. É importante citar que 11 agricultores da Associação compõem a Organização de Controle Social (OCS) Agricultores da Zona Leste. As OCS constituem uma das três formas de reconhecimento da agricultura orgânica previstas na Lei 10.831/2003. ${ }^{1}$

De forma sucinta, as OCS permitem o reconhecimento da qualidade orgânica por meio da relação de confiança estabelecida entre os produtores e os consumidores sem intermediários na comercialização de alimentos. Assim, as OCS preveem que os agricultores se organizem em processos de averiguação interna do cumprimento das normas da agricultura orgânica, o que lhes permite acessar circuitos curtos de proximidade, tendo reconhecimento oficial de qualidade orgânica. Além das feiras de produtores, os circuitos curtos de proximidade (CCP) compreendem os grupos de consumo responsável, programas públicos de abastecimento alimentar, entre outros (Darrot; Durant, 2010; Leão, 2019). A OCS Agricultores da Zona Leste é formada por cinco casais e um produtor autônomo e se organiza por meio das reuniões e visitas de averiguação que acorrem ao longo do ano.

A Cooperativa Agroverde, responsável pela comercialização de parte dos agricultores da zona norte, também acessa canais de via direta aos consumidores, notadamente dos bairros do entorno das áreas de produção. Ainda que não esteja vinculada a mecanismos de reconhecimento da produção orgânica, o 
manejo que realizam não inclui o uso de agrotóxicos. É importante acrescentar que a Cooperativa entregava, até 2016, seus produtos hortícolas para o PNAE atendendo os municípios de São Bernardo do Campo, Santo André, Suzano e São José dos Campos. Os outros produtores da zona norte também vendem seus produtos em feiras livres, pequenos mercados de bairro e diretamente na área de produção.

A Cooperapas possui uma gama de canais de escoamento maior e mais diversa, comparativamente à AAZL e à Cooperativa Agroverde, favorecendo a estabilidade de sua comercialização. Por outro lado, maior parte do alimento que fornece se desloca da zona sul (ZS) de São Paulo para as zonas mais centrais, onde os Índices de Desenvolvimento Humano (IDH) são mais elevados e são diversos os pontos de abastecimento alimentar, incluindo Institutos de Economia Solidária, a Rede Sesc e feiras de produtores. Os agricultores da Cooperapas também têm a sua produção orgânica reconhecida pelas outras duas modalidades previstas na Lei: a certificação participativa (SPG) e a certificação por auditoria privada. Além desses, alguns agricultores possuem o Protocolo de Transição Agroecológica, emitido pela Secretaria Estadual do Meio Ambiente. Por serem menos restritivas em relação aos mercados que as OCS, os agricultores podem acessar vias indiretas ao consumidor, sobretudo os restaurantes.

Os agricultores não cooperados da ZS vendem seus produtos na Ceagesp, em feiras livres ou para feirantes, em mercados locais e diretamente na área de produção. Trata-se de agricultores com maiores áreas, normalmente especializados em um tipo de cultura, com emprego de manejo convencional. Nota-se que produzem um volume mais expressivo e são mais adaptados aos mercados industrializados.

\section{Considerações finais}

O presente artigo buscou apresentar e caracterizar a agricultura existente no município de São Paulo, discutindo sua estimativa de produção e os principais canais de comercialização que têm sido acessados pelos agricultores.

Os dados demonstraram que o MSP possui uma agricultura produtiva e diversa, que não só abastece parte da demanda da população por alimentos, como compõe o território e a produção do espaço urbano. Mesmo assim, é de fundamental importância reconhecer a dificuldade em termos de assertividade em relação à agricultura no município, tendo em vista sua dinâmica e a multiplicidade de formas que assumem. É importante aprimorar as bases de dados e garantir que ajudem compreender a diversidade agrícola encontrada no território.

As alterações observadas na série histórica, no entanto, não parecem oferecer um quadro adequado do real crescimento que o setor da agricultura teve no município. É preciso considerar que podem apresentar subnotificações, especialmente nos levantamentos antigos, uma vez que a agricultura no MSP apenas recentemente teve sua importância reconhecida. A distinção entre o urbano e o rural, a ausência de reconhecimento de que as cidades podem ter produção 
agrícola dentro da malha urbana e as metodologias de pesquisas dos censos agropecuários são fatores que podem ter ocasionado subnotificações, impossibilitando estimar com precisão o crescimento da agricultura urbana no MSP. Mesmo assim, é possível sugerir que os dados mais recentes se aproximam mais da realidade encontrada no território.

Mesmo com dados subnotificados, observa-se um incremento na agricultura no MSP nos últimos 15 anos. A estruturação de políticas públicas para o setor, ${ }^{2}$ a abertura de feiras orgânicas e espaços de comercialização, além do crescimento identificado na produção agrícola municipal demonstram que há de fato um aumento e uma valorização das atividades agropecuárias no município.

No que se refere à comercialização, é oportuno destacar a pouca disponibilidade de dados oficiais publicados sobre o tema. Tendo em perspectiva as informações colhidas junto aos agricultores, destacam-se algumas observações a seguir. Primeiramente, nota-se a relação entre a produção agrícola de menor escala e os circuitos curtos de proximidade no MSP. Além disso, os agricultores vinculados a associações e cooperativas tendem a diversificar os seus canais de comercialização, garantindo maior estabilidade no escoamento e na geração de renda. Cabe também ressaltar a particularidade do papel de agentes exteriores às associações e cooperativas de agricultores e de instituições engajados com a AU, notadamente na comercialização.

As feiras livres e feiras orgânicas desempenham um papel importante no abastecimento da cidade com alimento mais saudável e fresco, e traz outros benefícios para os espaços urbanos como redução dos impactos ambientais na produção, armazenamento e comercialização. Tais modelos de comercialização ainda existentes no MSP beneficiam os produtores na manutenção de sua atividade agrícola. O papel dos pequenos mercados se dá, juntamente a esses outros canais diretos, principalmente na retenção dos alimentos produzidos no território para a população local. Quanto ao acesso às políticas públicas, a participação de programas de abastecimento que incorporam a AU ainda é incipiente.

Em tempos presentes e certamente futuros, a segurança alimentar nas cidades pode ser ameaçada por diferentes tipos de crises ambientais e financeiras, levando a grandes desigualdades de acesso e enormes consequências ao bem-estar humano. Portanto, conhecer melhor e certamente fomentar o seu potencial produtivo é um poderoso fator de preparo para melhor lidar com incertezas futuras.

Financiamento - Esta pesquisa foi possível graças ao financiamento e concessão de bolsa da Fundação de Amparo à Pesquisa do Estado de São Paulo (Fapesp), pelo processo 2017/14301-3, e da Coordenação de Aperfeiçoamento de Pessoal de Nível Superior (Capes), pelo Programa de Excelência Acadêmica (Proex). 
Notas

1 A Lei n.10.831/2003 dispõe sobre a produção e comercialização de produtos orgânicos no Brasil.

2 Dentre as políticas públicas para a agricultura no município de São Paulo, podemos citar o Programa de Agricultura Urbana e Periurbana (Proaurp - Lei n.13.727/04 e Decreto n.51.801/10), o Plano Diretor Estratégico do Município de São Paulo, o Projeto Ligue os Pontos entre outros.

\section{Referências}

AFSHIN, A. et al. Health effects of dietary risks in 195 countries, 1990-2017: a systematic analysis for the Global Burden of Disease Study 2017. The Lancet, v.393, n.10184, p.1958-1972, 2019.

BARON, B. C. Agroecologia e urbanidade: uma investigação a partir da agricultura urbana na Região Metropolitana de São Paulo. São Paulo, 2017. Trabalho de Graduação (Bacharelado em Geografia) - Faculdade de Filosofia, Letras e Ciências Humanas, Universidade de São Paulo.

BIAZOTI, A. R. Engajamento politico na agricultura urbana: a potência de agir nas hortas comunitárias de São Paulo. Piracicaba, 2020. Dissertação (Mestrado em Ecologia Aplicada) - Centro de Energia Nucleal na Agricultura, Escola Superior de Agricultura "Luiz de Queiroz”, Universidade de São Paulo.

BIAZOTI, A. R.; SORRENTINO, M. Agricultura urbana no município de São Paulo: uma proposta de caracterização. Conference Proceedings: Third International Conference on Agriculture and Food in an Urbanizing Society. Porto Alegre: UFRGS/FAO, 2018.

BORGES, C. A.; CABRAL-MIRANDA, W.; JAIME, P. C. Urban Food Sources and the Challenges of Food Availability According to the Brazilian Dietary Guidelines Recommendations. Sustainability, v.10, 4643, 2018; Special Issue Urban Food Deserts: Perspectives from the Global South, 2018.

CALDAS, E. de L.; JAYO, M. Agriculturas urbanas em São Paulo: histórico e taxonomia. Confins, Paris, v.29, 2019.

CARNEIRO, M. J.; MALUF, R. S. Multifuncionalidade da agricultura familiar. Cadernos do CEAM, p.43-58, 2005.

CARREFOUR. Localizador de Lojas. Disponível em: <https://www.carrefour.com.br/ localizador-de-lojas>. Acesso em: 12 mar. 2020.

CEAGESP. Companhia de Entrepostos e Armazéns Gerais do Estado de São Paulo. Entrepostos: Capital - ETSP. 2020. Disponível em: <http://www.ceagesp.gov.br/entrepostos/etsp/>. Acesso em: 26 mar. 2020.

DARROT, C.; DURANT, G. Référenciel central des circuits courts de proximité: mise en évidence et statut pour l'action. Circuits courts: Contribution au dépeloppement régional. Ouvrage collectif, INRA. Dijon: Educagri Éditions, 2010. 224p.

GIATTI, L. L. et. al. Nexos de exclusão e desafios de sustentabilidade e saúde em uma periferia urbana no Brasil. Cadernos de Saúde Pública. v.35, e00007918, 2019. 
GPA. Grupo Pão de Açúcar. Onde estamos. Disponível em: <https://www.gpabr.com/ pt/conheca-o-gpa/onde-estamos/>. Acesso em: 12 mar. 2020.

IBGE. Instituto Brasileiro de Geografia e Estatística. Censo Agropecuário 2006. IBGE, 2006.

. Produção Agrícola Municipal 2016. Rio de Janeiro: IBGE, 2017.

Censo Agropecuário 2017. IBGE, 2018.

Censo agropecuário: resultados definitivos 2017. Rio de Janeiro: IBGE, 2019. Disponível em https://biblioteca.ibge.gov.br/visualizacao/periodicos/3096/ agro_2017_resultados_definitivos.pdf. Acesso em: 10 fev. 2021.

INSTITUTO ESCOLHAS E URBEM, Cartografias, Mais perto do que se imagina: os desafios da produção de alimentos na metrópole de São Paulo, 2020.

LEÃO, V. O. P. S, Organizações de Controle Social na Região Metropolitana de São Paulo: relações de proximidade e de confiança em foco. Piracicaba, 2019. Dissertação (Mestrado em Ecologia Aplicada) - Centro de Energia Nucleal na Agricultura, Escola Superior de Agricultura “Luiz de Queiroz”, Universidade de São Paulo.

McCLINTOCK, N. Radical, reformist, and garden-variety neoliberal: coming to terms with urban agriculture's contradictions. Local Environment Journal, v.19, n.2, p.147$71,2014$.

MINAYO, M. C. S. Amostragem e saturação em pesquisa qualitativa: consensos e controvérsias. Revista Pesquisa Qualitativa, São Paulo, v.5, n.7, p.1-12, abril 2017.

MOUGEOT, L. J. A. Agricultura Urbana - conceito e definição. Revista de Agricultura Urbana, 1, Resource Centre on Urban Agriculture and Forestry - RUAF, 2000.

NAGIB, G. Agricultura urbana como ativismo na cidade de São Paulo: o caso da Horta das Corujas. São Paulo, 2016. 434p. Dissertação (Mestrado em Geografia) - Faculdade de Filosofia, Letras e Ciências Humanas, Universidade de São Paulo.

OPITZ, I. et al. Contributing to food security in urban areas: differences between urban agriculture and peri-urban agriculture in the Global North. Agric Hum Values, v.33, p.341, 2016.

PESSOA, C.C.; SOUZA, M. de; SCHUCH, I. Agricultura urbana e Segurança Alimentar: estudo no município de Santa Maria - RS. Segurança Alimentar e Nutricional, v.13, n.1, p.23-37, 2006.

SÃO PAULO. Prefeitura Municipal de São Paulo. Agricultores recebem certificado de orgânico. Notícia veiculada em 21/7/2017. Disponível em: <http://www.prefeitura.sp.gov.br/cidade/secretarias/regionais/sao_mateus/noticias/index.php?p=74336>. Acesso em: 24 maio 2018.

Prefeitura Municipal de São Paulo. Cadastramento de Unidades Produtivas, 2019. Projeto Ligue os Pontos. Disponível em: <https://ligueospontos.prefeitura.sp.gov. br/agricultura-familiar/cadastro/>. Acesso em: 17 fev. 2020.

Dados Abertos, Refeições Servidas - 2018. Disponível em: <http://dados.prefeitura.sp.gov.br/it/dataset/alimentacao-escolar-relatorio-de-refeicoes-servidas/resource/lb06faae-4964-4387-8583-c4f17827519b>. Acesso em: 12 mar. 2020. 
SÃO PAULO. Prefeitura Municipal de São Paulo. GeoSampa-Mapa, 2020. Disponível em: <http://geosampa.prefeitura.sp.gov.br/PaginasPublicas/_SBC.aspx>. Acesso em: 11 mar. 2020.

. Projeto Ligue os Pontos, Relatório da fase 1, 2018. Disponível em: <https://gestaourbana.prefeitura.sp.gov.br/wp-content/uploads/2019/01/RELAT\%C3\%93RIO_ SITE_PTBR.pdf>. Acesso em: 27 mar. 2020.

Secretaria Municipal de Desenvolvimento Econômico e Trabalho. Feira Maps. Disponível em: <https://www9.prefeitura.sp.gov.br/secretarias/sdte/pesquisa/feiras/lista_completa.html>. Acesso em: 11 mar. 2020.

SÃO PAULO (Estado). Secretaria de Agricultura e Abastecimento do Estado de São Paulo. Projeto LUPA 2007/2008: Censo Agropecuário do Estado de São Paulo. São Paulo: Instituto de Economia Agrícola. Coordenadoria de Desenvolvimento Rural Sustentável, 2009.

Secretaria de Agricultura e Abastecimento do Estado de São Paulo. Projeto LUPA 2016/2017: Censo Agropecuário do Estado de São Paulo. São Paulo: Instituto de Economia Agrícola. Coordenadoria de Desenvolvimento Rural Sustentável, 2019.

SWINBURN, B. A. et al. The global syndemic of obesity, undernutrition, and climate change: the Lancet Commission report. The Lancet, v.393, n.10173, p.791-846, 2019.

VALDIONES, A. P. G. Panorama da agricultura urbana e periurbana no município de São Paulo. São Paulo, 2013. Dissertação (Mestrado) - Programa de Pós-Graduação em Mudança Social e Participação Política, Escola de Artes, Ciências e Humanidades, Universidade de São Paulo.

WILLETT, W. et al. Food in the Anthropocene: the EAT-Lancet Commission on healthy diets from sustainable food systems. The Lancet, v.393, n.10170, p.447-92, 2019.

RESUMO - A Agricultura Urbana (AU) tem sido apontada, mais recentemente, como elemento importante nos discursos e nas práticas que visam à segurança alimentar urbana. O presente artigo procurou discutir a produção agrícola do Município de São Paulo (MSP) e seu escoamento, considerando a diversidade de perfis que a AU pode assumir. Para tal, foi avaliada a produção agrícola em bases de dados oficiais. No que se refere à comercialização, foram coletadas informações em sete entrevistas semiestruturadas com agricultores do MSP entre 2018 e 2020 . Os principais resultados encontrados indicam que houve um crescimento das práticas agropecuárias no município, acessando uma ampla variedade de canais de comercialização. A abertura de novos mercados, o desenvolvimento de políticas públicas e o reconhecimento público foram essenciais para o crescimento da agricultura no MSP.

PALAVRAS-CHAVE: Agricultura urbana, Município de São Paulo, Produção agropecuária, Comercialização.

ABSTRACT - Urban agriculture (UA) has recently been pointed out as an important element in the discussion and practices of urban food security. This article seeks to discuss agricultural production and distribution in the city of São Paulo, considering the diversity of profiles that UA can assume. To this end, official databases were used to compute agricultural production. With regard to commercialization, information was collected from seven semi-structured interviews with farmers of the city of São Paulo between 
2018 and 2020. The main findings indicate that there was an increase in agricultural practices in the city, encompassing a wide variety of commercialization channels. The opening of new markets, the development of public policies and public recognition were essential for the growth of agriculture in the city of São Paulo.

KErWORDS: Urban agriculture, City of São Paulo, Agricultural production, Commercialization.

André Ruoppolo Biazoti é membro do Grupo de Estudos em Agricultura Urbana (GEAU), Instituto de Estudos Avançados (IEA), Universidade de São Paulo (USP). @ - andrebiazoti@gmail.com / https://orcid.org/0000-0001-7132-0376.

Vitória Oliveira P. de Sonza Leão é membro do Grupo de Estudos em Agricultura Urbana (GEAU), Instituto de Estudos Avançados (IEA), Universidade de São Paulo (USP). @-vitorialeao.usp@gmail.com / https://orcid.org/0000-0003-3595-5002.

Rafael Junqueira Buralli é consultor do Departamento de Saúde Ambiental, do Trabalhador e Vigilância das Emergências em Saúde Pública (DSASTE) do Ministério da Saúde e membro do Grupo de Estudos em Agricultura Urbana (GEAU), Instituto de Estudos Avançados (IEA), Universidade de São Paulo (USP). @ - rafael.buralli@gmail.com / https://orcid.org/0000-0001-7006-6177.

Thais Mauad é professora associada do Departamento de Patologia, Faculdade de Medicina (FM), Universidade de São Paulo (USP). @ - tmauad@usp.br / https://orcid.org/0000-0002-3354-1466.

Recebido em 10.9.2019 e aceito em 20.4.2020.

I, II, III Universidade de São Paulo, Instituto de Estudos Avançados, Grupo de Estudos em Agricultura Urbana, São Paulo, Brasil.

IV Universidade de São Paulo, Faculdade de Medicina, Departamento de Patologia, São Paulo, Brasil. 
